\title{
O uso do método história oral nas pesquisas qualitativas: contribuições para a temática do cuidado em saúde mental
}

\section{Use of the method oral history in qualitative research: contributions for the mental helth care thematic abstract}

\author{
Mara Cristina Ribeiro* \\ Universidade Estadual de Ciências da Saúde de Alagoas - UNCISAL, Alagoas, \\ Maceió, Brasil
}

\section{Ana Lúcia Machado**}

Universidade de São Paulo - USP, São Paulo, São Paulo, Brasil

\begin{abstract}
RESUMO
As pesquisas qualitativas em saúde mental vêm priorizando investigações sobre o cuidado percebido dentro de uma conjuntura de transformações sociais, políticas, culturais, ideológicas e comportamentais que têm marcado a saúde mental nos últimos anos. O artigo objetiva discutir o uso do método da história oral desde a sua concepção até os dias atuais e sua possível contribuição nas pesquisas qualitativas em saúde mental dentro desse novo contexto. A história da assistência psiquiátrica sempre esteve permeada por experiências de exclusão e estigmatização, e o uso desse método possibilita dar voz àqueles que durante anos foram silenciados, bem como narrar a história da transformação da atenção em saúde mental, na perspectiva dos novos protagonistas do cuidado.
\end{abstract}

Palavras-Chave: pesquisa qualitativa, história oral, saúde mental.

\begin{abstract}
The qualitative research in mental health have been prioritizing investigations over the perceived care within a conjecture of social, political, cultural, ideological and behavioral changes that have been marking the mental health field in the past years. The article aims to discuss the Oral History methodology since its conception until the present days and its possible contributions to the qualitative research in mental health within this new context. The history of psychiatry assistance has always been permeated by experiences of exclusion and stigmatization, and the usage of this methodology allows ones to give voice to those who for years were silenced, as well as narrates the history of the transformations of the care offered in mental health in the perspective of the new protagonists of attention.
\end{abstract}

Keywords: qualitative research, oral history, mental health

\section{Introdução}


As descrições históricas se ordenam pela atualidade do saber, se multiplicam com suas transformações e não deixam de romper com elas próprias. A história de um conceito não é, de forma alguma, a de seu refinamento progressivo, de sua racionalidade continuamente crescente, de seu gradiente de abstração, mas a de seus diversos campos de constituição e validade, as de suas regras sucessivas de uso, a dos meios teóricos múltiplos em que foi realizada e concluída sua elaboração (Foucault, 2000).

O homem, como ser histórico e social, sempre procurou conhecer o universo que o circunda e esse interesse coloca-o como à frente de um espelho, onde o desafio maior é conhecer-se, aprofundando-se em sua problemática, a problemática humana. A forma de alcançar este conhecimento necessita da utilização de um método para que possíveis variantes sejam consideradas. O corpo de conhecimento ou a filosofia que ampara um método garante a ele e ao produto final de sua procura, o reconhecimento de um rigor científico que afiança uma maior consistência ou confiabilidade aos resultados finais.

A realização de uma pesquisa com base na compreensão, olhar e vivência dos atores implicados no fenômeno investigado solicita a escolha de um método que considere as especificidades do objeto de conhecimento e possibilite o entendimento do contexto de pesquisa e da dimensão da experiência humana o mais próximo da realidade.

A pesquisa qualitativa apresenta-se como uma orientação cada vez mais difundida no campo da atividade científica neste início do século e se constitui como uma modalidade de investigação bastante empregada e aceita na área da saúde e das ciências sociais (Bosi \& Mercado-Martínez, 2007).

Ela valoriza a figura do sujeito e de seus significados na produção dos resultados, pois se aplica ao estudo da história, das relações, das representações, das crenças, das percepções e das opiniões, produtos das interpretações que os humanos fazem a respeito de como vivem, sentem, pensam e constroem seus artefatos e a si mesmos (Minayo, 2008).

O propósito comum das abordagens qualitativas é a busca por analisar o significado atribuído pelos sujeitos aos fatos, relações e práticas, portanto elas privilegiam o setting natural, envolvendo a observação de situações reais e cotidianas (Deslandes, 2008). Entre os diversos tipos metodológicos de produção de dados passíveis de uso na pesquisa qualitativa, o método escolhido deve ser definido a partir da construção do objeto, pois deve ancorá-lo teórica e metodologicamente. As pesquisas qualitativas em saúde mental vêm priorizando investigações sobre o cuidado percebido dentro de uma conjuntura de transformações sociais, políticas, culturais, ideológicas e comportamentais que têm marcado a saúde mental nos últimos anos. 
Essas transformações, com toda a sua carga histórica, não poderiam ser medidas ou reduzidas a avaliações numéricas ou dados estatísticos. Por sua riqueza e complexidade, necessita de um olhar que penetre transversalmente as várias facetas que a compõe - seus sujeitos, suas histórias e vivências, os processos de construção envolvidos, seus limites e desafios. A história oral é um dos métodos que compõem o campo mais amplo da pesquisa qualitativa e tem se constituído como instrumento bastante relevante na área das ciências humanas, sendo utilizado na atualidade por psicólogos, sociólogos, antropólogos, historiadores e terapeutas ocupacionais (Silva \& Barros, 2010).

\section{Caracterização da História Oral}

A fonte oral é a base primária para a obtenção de qualquer forma de conhecimento, seja ele científico ou não, o que vai dar legitimidade científica serão os critérios adotados na busca desse conhecimento. As narrativas ganharam caráter científico quando os argumentos foram sistematizados, arranjados metodologicamente, equiparados uns aos outros em diálogo continuado e cumulativo e assumidos profissionalmente (Meihy, 2005).

As entrevistas, portanto, foram e ainda são largamente utilizadas como recurso para construir informações no campo científico. A história oral representa um tipo de entrevista, porém, exibe uma complexidade que tentaremos descrevê-la ao longo dessas linhas. Depois do fim da Segunda Guerra Mundial foi criado o primeiro projeto formal de história oral, na Universidade de Columbia, em Nova York. Foram os critérios estabelecidos que a diferenciaram das demais formas conhecidas de entrevistas. O nascimento da moderna história oral combinou a necessidade de narrativas de experiências de pessoas e os avanços e ampliação dos meios de comunicação (Grele, 2001).

Segundo Meihy (2005, p.93) a história oral, de início, "combinou duas funções complementares: 1) a de registrar e 2) a de divulgar experiências relevantes e estabelecer ligações com o meio urbano que consumia as entrevistas, promovendo assim um incentivo para a compreensão e o registro da história local", indicando, assim, o seu compromisso público no interesse da coletividade.

O desenvolvimento tecnológico passou a ser grande aliado da evolução e reconhecimento dessa prática de apreensão de narrativas, podendo-se afirmar que três elementos constituem até hoje a relação mínima da história oral: o entrevistador, o entrevistado e o gravador (ou qualquer outro meio eletrônico de registro pontual das falas).

A necessidade de relatar, de contar e registrar as angústias vividas logo após a guerra deu à luz a esta nova ciência no campo da 
história, porém, apesar de ter seu início em 1948 nos Estados Unidos, a História Oral só se consolidou a partir da década de 1960, quando foi difundida fora de suas fronteiras (J outard, 1983).

A adesão de vários estudiosos, entre eles Paul Thompson, na Inglaterra, Mercedes Vilanova, na Espanha e Danièle Hanet, na França, pode ser apontado como um dos aspectos indicativos da expansão de seu uso na Europa (Reinaldo, Saeki, Reinaldo, 2003).

No Brasil, o golpe militar de 1964, entre incontáveis prejuízos na construção do conhecimento de uma forma geral e avanços na conscientização sociopolítica da população, também influenciou de forma negativa o desenvolvimento da história oral, pois, coibiu projetos e registros que gravassem experiências, opiniões ou depoimentos. Na década de 1970, tentativas de resistência foram feitas, destacando-se a criação do Centro de Pesquisa e Documentação de História Contemporânea do Brasil da Fundação Getúlio Vargas. A parceria dessa fundação com a Fundação Ford e a publicação em 1979 do texto História oral: teoria e técnica, de C.H.P. Correia teve como intuito estruturar uma organização ampla e de alcance nacional, porém pela falta de ambiente democrático essas ações não frutificaram (Meihy, 2005; Reinaldo, Saeki, \& Reinaldo, 2003).

Importante destacar que a história oral tem relevante função política, pois se compromete com a democracia - por ser condição para sua realização - e, com o direito de saber - por permitir veicular opiniões variadas sobre temas do presente (Meihy, 2005). Posto isso, pode-se afirmar que apenas a partir dos anos 1980, no período da abertura política, é que as universidades e instituições voltadas para a preservação da memória passaram a criar um número crescente de programas de história oral. Segundo Ferreira (1997), o número de pesquisadores que usavam a metodologia na elaboração de dissertações e teses foi se tornando expressiva igualmente após este período. A autora ainda afirma que foi apenas no início dos anos 90 que houve um verdadeiro boom da história oral, que pode ser explicado a partir de mudanças no campo da história, com o rompimento do paradigma estruturalista, mas também a partir de transformação mais gerais na sociedade brasileira. A autora expõe os aspectos mais importantes de tais mudanças no campo da pesquisa histórica: “(...) revalorizou-se a análise qualitativa, resgatou-se a importância das experiências individuais, ou seja, deslocou-se os interesses das estruturas para as redes, dos sistemas de posições para as situações vividas, das normas coletivas para as situações singulares" (Ferreira, 1997, p.3).

Com relação à sua conceituação, Meihy, em seu Manual de história oral (2005) destaca que a história oral é uma prática de apreensão de narrativas feitas através do uso de meios eletrônicos e destinada a recolher testemunhos, promover análises de processos sociais do 
presente e facilitar o conhecimento do meio imediato. Afirma ainda ser um recurso moderno usado para a elaboração de documentos, arquivamento e estudos referentes à experiência social de pessoas e de grupos, sendo sempre uma história do "tempo presente" e também reconhecida como "história viva".

Com relação ao seu uso, a história oral pode se apresentar em três formas diferentes, dependendo do conteúdo trabalhado nas entrevistas: História Oral de Vida, Tradição Oral e História Oral Temática. A História Oral de Vida constitui a narrativa do conjunto de experiências de uma pessoa; a Tradição Oral trabalha com a permanência dos mitos e com a visão de mundo das comunidades que têm valores filtrados por estruturas mentais, asseguradas em referência ao passado remoto; e a História Oral Temática, em que o compromisso é a elucidação ou a opinião do narrador sobre algum evento definido (Meihy, 2005).

É possível apontar, no uso da história oral, elementos bastante importantes em sua metodologia: pressupõe, primeiramente, a existência de um programa de reconstituição histórica sobre algum tema específico; a escolha dos entrevistados não pode ser aleatória, pois é fundamental a listagem de atores que poderão fornecer contribuições que podem variar de úteis a imprescindíveis ao desvelamento do tema; a organização do roteiro da entrevista pressupõe o conhecimento profundo do tema em questão, obtido através de todas as fontes disponíveis (livros, jornais, documentos, anuários) (Haguette, 2010).

O grande desafio é o de transmitir a fala do outro com o mínimo de interferência possível, respeitando seus valores e suas vivências. Os conceitos e ideias levantados devem ser tratados com grande respeito e a maior responsabilidade é a de interpretá-los de forma a não modificá-los, mas, sim, destacá-los com a sensibilidade de um ouvinte disposto a aprender com a experiência e conhecimento do outro.

\section{A História Oral e as transformações do cuidado em saúde mental}

O valor e uso do método de história oral em pesquisas interessadas em conhecer de forma aprofundada fatos de uma certa comunidade sob a perspectiva de seus sujeitos, justifica-se porque esta traz a história para dentro da comunidade e a extrai de dentro da comunidade, transformando os objetos de estudo em sujeitos, uma vez que passa a admitir vozes desconhecidas, menos privilegiadas e, paralelamente, propõe o desafio de um novo sentido social da história, ao valorizar fontes eliminadas pela exclusividade da tradição 
documental, que elege o testemunho escrito como fonte neutra, fidedigna e objetiva (Thompson, 1992).

A presença do passado no presente imediato das pessoas é a razão de ser da história oral, pois além de oferecer uma mudança do conceito de história, garante sentido social à vida de depoentes e leitores, que passam a entender a sequência histórica e a se sentirem parte do contexto em que vivem; nesse sentido, ela se fundamenta no direito de participação social e, portanto, está ligada à consciência da cidadania (Meihy, 2005).

Basear a investigação na produção de um pensamento sobre a experiência vivida significa centrá-la nas representações dos sujeitos, o que constitui a opção de se estudar uma realidade social e coletiva por meio de narrativas individuais e vividos singulares. Trata-se, assim, da reprodução do fato social na experiência vivida e na reflexão que a relata, sendo cada relato a forma pessoal de expressar o grupo ou o social, o que cada pessoa relata, e o modo como relata, são construções que se determinam na vida em sociedade (Schairaiber, 1995).

Desta forma, a história oral contrapõe-se ao modo hegemônico e legitimado de fazer ciência, ou seja, ao modo positivista. Este, com seus ideais de objetividade e neutralidade, elege determinados discursos como verdadeiros e considera outros como falsos (Mendonça Filho \& Vasconcelos, 2010). A história oral, por outro lado, prioriza a fala do sujeito em seu contexto, foca o seu objeto nos saberes locais, em falas que se legitimam a partir da experiência vivida no cotidiano das transformações sócio-políticas de territórios, comunidades e instituições a serem estudadas.

Considerando que uma série de transformações no mundo do trabalho, nas relações entre pessoas, nas inovações tecnológicas, vêm impondo novas maneiras de organizar a produção em saúde no Brasil, a mudança que se opera traz a marca do fortalecimento do cuidado, da ação intersetorial e do desenvolvimento da autonomia. O Sistema Único de Saúde (SUS) procura romper a lógica produtivista dos serviços e implantar práticas fundadas no conceito ampliado de saúde, exigindo novas abordagens para a produção do conhecimento e para a intervenção prática (Tavares, 2005).

O processo de construção da Reforma Psiquiátrica no Brasil iniciou-se entre os anos de 1970 e 1980, paralelamente à redemocratização do país. Dentro desse contexto histórico, toda a Saúde passava por um processo de reconstrução. Vislumbrava-se uma nova concepção sobre o binômio saúde-doença, gerando modelos de atenção, nos quais as respostas aos problemas de saúde não fossem encontradas, unicamente, nos serviços médicos e que o próprio conceito de Saúde não fosse definido como ausência de doença.

A noção de saúde dessa forma passa a ser ampliada, ampliam-se também os campos de ação, uma vez que saúde, nesse sentido, está 
conectada com a noção de vida, de qualidade de vida. Dessa forma, múltiplas dimensões estão envolvidas nesse processo de promoção de saúde, tanto no âmbito global de um Estado, quanto no âmbito da singularidade e autonomia dos sujeitos (Czeresnia \& Freitas, 2003).

No campo da saúde mental, essas noções também vão sendo incorporadas e, a partir daí, vão surgindo novas propostas de intervenção que pedem mudanças na estrutura institucional, bem como na estrutura individual, social e política. O modelo asilar passa a ser efetivamente criticado e a necessidade de criação de um novo modelo de atenção à população em sofrimento psíquico passa a ser solicitado através de mobilizações em diversas esferas da sociedade. O cuidado passa a ocupar um lugar privilegiado, constituindo um outro sujeito, não um objeto do sujeito técnico, mas um outro verdadeiro sujeito na relação terapêutica, a ação cuidadora passa a ser entendida como atitude e espaço de reconstrução de intersubjetividades, apoiada na tecnologia mas não resumida a ela (Ayres, 2000).

$\mathrm{Na}$ continuidade histórica das transformações no contexto brasileiro, seguindo a lógica de descentralização do SUS, foi sendo estimulada a constituição de redes de atenção psicossocial que trabalhassem em direção à implantação de uma rede integrada de base comunitária, com ofertas complexas de atenção, sob a diretriz da Atenção Psicossocial. Na atualidade, esta rede de atenção em saúde mental pode ser composta por setores da atenção básica, como as unidades básicas de saúde, as equipes de saúde da família e os Núcleos de Apoio à Saúde da Família (NASF); por serviços especializados como os Centros de Atenção Psicossocial (CAPS), os ambulatórios de saúde mental, hospitais-dia e os Centros de Convivência e Cultura; além de serviços de urgência e emergência psiquiátrica, leitos ou unidades em hospital geral e as residências terapêuticas. Nos últimos anos, essa rede tem sido ampliada por se articular com outros serviços e setores das mais diversas áreas, com o objetivo de dar respostas globais às necessidades de (re)inserção de seus usuários. Dessa forma, tem sido reforçada a necessidade de realização de ações intersetoriais.

Novos conceitos têm sido introduzidos nesta esfera, conceitos que dificilmente conseguem ser captados sem a abertura de espaço à narrativa, pois só podem ser reconhecidos no campo da subjetividade e das relações intersubjetivas. Desta forma, pesquisadores interessados em investigar essas novas estruturas devem se aproximar de metodologias que possibilitem a expressão de vivências tais como: o cuidado na crise, o sofrimento psíquico, a clínica ampliada, as estratégias de acolhimento, o resgate da cidadania, a tomada de responsabilidade, a ampliação de potencialidades, o trabalho em equipe e a ação interdisciplinar, o reflexo dos grupos\oficinas terapêuticas na inclusão, a continência das redes de 
atenção, o cuidadolapoio aos familiares, a ação no território, entre outros.

Portanto, o cuidado exercido nos novos dispositivos de atenção à saúde mental tem esse grande diferencial - coloca em foco o sujeito e não a doença; bem como traz em sua prática o compromisso de oportunizar a inclusão de seus usuários nas diversas esferas de trocas no cotidiano da vida. Para tanto é preciso conhecer em profundidade atores (usuários, trabalhadores, familiares, entre outros) e serviços envolvidos nesse cuidado.

Apesar das significativas transformações da assistência em saúde mental ocorridas nos últimos anos, verificam-se poucas pesquisas que abordam o cuidado sob esta nova perspectiva. Pesquisas que favoreçam a apreensão da riqueza subjetiva dos sentidos de seus diferentes protagonistas inseridos no contexto dessas mudanças (Campos \& Furtado, 2008; Brêda, Ribeiro, Silva, Silva, \& Costa, 2011).

Como apontam Campos e Furtado (2008) as práticas que ocorrem nos serviços de saúde nos novos cenário do SUS precisam ser avaliadas e estudadas, porém, as abordagens metodológicas tradicionais não têm se mostrado capazes de dar conta dessas transformações. Neste sentido, a história oral pode ser um grande instrumento de modificação dessa realidade, pois ela possibilita a produção de informações ainda não existentes que, por meio de narrativas, registra as transformações no cuidado, aprofundando-se nas experiências vividas, nas percepções e expectativas deste novo contexto.

\section{Algumas histórias trazidas pela História Oral}

Com o propósito de fazer emergir a vivência, a experiência e a percepção de alguns protagonistas das transformações do cuidado em saúde mental, foi realizado estudo com usuários e familiares dos serviços substitutivos ao hospital psiquiátrico, os Centros de Atenção Psicossocial e seus trabalhadores. A pesquisa buscou captar a percepção sobre as transformações ocorridas no Estado de Alagoas, com relação ao cuidado em saúde mental e a descrição de suas histórias relacionadas a essas mudanças. Para tanto foi utilizada a técnica de História Oral Temática.

Foram selecionados como locais da pesquisa os dois CAPS mais novos do interior do estado e da capital, Maceió, e os dois CAPS mais antigos também do interior e da capital, totalizando quatro instituições. Nelas, foram ouvidos cinco usuários, quatro familiares e oito trabalhadores. A escolha dos CAPS como campo para a produção dos dados deve-se ao fato de que em Alagoas esses são os únicos serviços substitutivos ao hospital psiquiátrico. 
A pesquisa procurou aprofundar o olhar sobre as pessoas que representam os sujeitos do cuidado, procurou conhecer quem são essas pessoas, como elas se percebem como sujeito de sua história e dentro dessa nova composição do cuidado.

A seguir fazemos um pequeno recorte dos dados produzidos para demonstrar a potencialidade da técnica da História Oral. Para garantir o sigilo dos sujeitos que participaram do estudo utilizaremos as siglas (U) para usuários, (F) para familiares e (T) para trabalhadores.

Ao se referirem às suas histórias de vida e situações vividas, as falas de nossos entrevistados são carregadas de imagens ligadas à doença e seu sofrimento:

(...) eu era uma pessoa que tinha muita depressão com qualquer coisa, com a caneta, como eu passei a dizer a você, com as cores, cores verde, cores amarela ou preta, aquelas cores me indicavam um sentido... o preto significava o pecado, o vermelho significa o sangue derramado na face da terra, o verde significava a esperança ... (U2)

"E se diagnosticou de tudo: no Rio Grande do Sul, que eu tinha esquizofrenia, que eu era bipolar, tudo, de tudo.... Aí chegaram a conclusão que era autismo, o Asperger, o leve..." (U4)

“(...) só que ela vivia numa situação que ela tirava a roupa, ficava pelada, andava por todo canto, uma situação triste, pesada.... Ela ficava agitada, ficava agressiva, ficava nervosa... (F1)"

A vivência de ser diferente, de sentir ou perceber o mundo de forma diferenciada e manifestar-se contrariamente ao que a maioria espera, marca o início do sofrimento psíquico. Preconceito, discriminação, segregação, estigma, exclusão, são palavras bastante usadas nos relatos de nossos interlocutores: “(...) porque as famílias que têm um parente com necessidades especiais o tratam como se fossem uma cruz pra carregar, um martírio. Você joga em casa, não deixa sair..." (U4)

A gente ouve falar que tem pessoas que mantêm pacientes presos porque assim, na verdade transtorno mental ainda é uma coisa assim muito pesada pra família e então as pessoas ainda têm aquela visão passada de segregar e pronto. (T1)

É muito difícil você trabalhar com saúde mental, existe ainda muito preconceito, o estigma do louco também é muito difícil você trabalhar, tanto é que quando a gente passa, o povo 
pergunta: 'trabalha aonde? No CAPS? Ah... lá no lugar dos doidos...' Então assim, existe muito preconceito... (T2)

(...) às vezes nos grupos eles [os usuários] falam muito isso 'olhe eu vinha no ônibus, no ônibus escolar e quando descobriram que eu era do CAPS começaram a dizer: olhe o doido, é o doido' então já começa a ser colocado de escanteio ... (T3)

Essas falas corroboram a ideia de que há dor e sofrimento para além da manifestação sintomatológica do transtorno mental, a dor sentida e vivida pelas pessoas com história de transtorno mental também está na relação que a família e a sociedade, de uma maneira geral, estabelecem com essas pessoas. Portanto, o campo de ação para esse novo cuidado deve priorizar este importante aspecto.

Ao se referirem ao cuidado recebido nos dois campos assistenciais, o hospital psiquiátrico e o CAPS, os usuários e familiares trazem impressões e experiências vividas bastante significativas:

A primeira vez que eu pisei num hospital psiquiátrico foi lá no ....Lá... lá é desumano.... Não tem jeito. A família vai lá, e joga lá, e fica por lá mesmo.... O CAPS é uma tentativa assim de humanizar, né? Quer dizer que quem tem transtorno mental, uma deficiência mental, não é inútil, não é largado, não é perigo, não é? (U4)

“Quando eu fui pra o hospital(...), pra mim foi um inferno... Não é muito bom pras pessoas, estar lá, porque eu passei um sofrimento danado... Sofri demais... E aqui (CAPS) é o melhor lugar que tem". (U5)

(...) que aqui [CAPS] faz de conta que é em casa (...) é perto de casa.... E lá no hospital, minha filha, ele só faltava morrer de fome, porque ele não comia a comida de lá, só comia quando eu levava de casa ou pagava na cantina pra ele comer. Aqui eu acho melhor. (F2)

"Eu gosto do tratamento do CAPS. Eu gosto do tratamento do CAPS porque o CAPS não lhe amarra, e no hospital amarrava ele..." (F4)

As falas dos trabalhadores também trazem a representação do contexto histórico e da atualidade:

A construção dos CAPS veio realmente pra evitar que pessoas sejam simplesmente amontoadas num espaço e lá sejam 
esquecidas (...) os CAPS vieram com o intuito de tirar, de não animalizar o homem, e eu acho que é esse o ponto mais importante. (T1)

(...) era um tratamento muito desumano, você manter pessoas presas como animais, assim de maneira muito desumana, então essa nova proposta do tratamento em saúde mental ela veio realmente humanizar essa relação profissional e paciente, profissional e família, família e paciente. (T2)

Um dos principais aspectos apontado como qualificador na caracterização do novo cuidado em saúde mental exercido em Alagoas, foi o fato de ele estar dirigido para uma política e prática de inclusão: “(...) o usuário que é atendido em CAPS, ele tem uma socialização melhor, ele mantém o contato direto com a família, não há o afastamento, as problemáticas são menores, entendeu?" (T3)

(...) todas as ações de você incluir o doente mental na sociedade, com as diversas formas de contar com as diversas instituições, você favorecer a inclusão social, a possibilidade de você quebrar toda essa contenção, de passar para a sociedade que ela tem que se transformar para entender o portador de transtorno mental. (T5)

Essas falas trazem a ideia de que o cuidado dirigido aos usuários dos CAPS deve sempre levar em conta a potência de vida existente nos sujeitos, a potência de trilhar novos caminhos, alcançar novos objetivos, e criar novos desejos. Resgatar este sujeito da vivência exclusiva da doença e dos encargos que esta traz é trazê-lo a uma nova constituição de vida que não se faz no entorno apenas do indivíduo, mas se faz no entorno da sociedade e da cultura que a rege.

Somente com o trabalho de construção de um lugar social real para esses sujeitos é que eles poderão dar liberdade aos seus desejos e realizar seus sonhos: "Eu quero sempre minha evolução, meu progresso, melhoria... Quero ter vida social, vida afetiva, quero vida profissional..." (U4)

“(...) fazer ele [o usuário] ir mais adiante, vendo as possibilidades de reintrodução desse portador no mercado de trabalho, na profissionalização". (T5)

"Eu vendo caneta, chaveiro, agenda telefônica, papel de presente, caixa de presente e aí vai... Aí eu trago aqui. O pessoal gosta muito. O meu trabalho é um trabalho bonito, todo mundo gosta..." (U5) 
As novas proposições de cuidado em saúde mental tiram do foco a doença e passam a focar o sujeito e, é por isso, que o estabelecimento de novos espaços para o exercício desse cuidado é tão necessário. Espaços onde trocas reais sejam incitadas e potencializadas, que possam reconhecer as necessidades e diferenças de cada sujeito, que estendam as suas ações à comunidade, ao território e à cidade nos seus mais diversos setores.

Desta forma, ao considerarmos o cuidado em saúde mental um fenômeno complexo, socialmente construído e que deve ser analisado dentro de uma realidade histórica que o circunda e o determina, as pesquisas desenvolvidas nesse campo devem partir do sentido que seus agentes the conferem, priorizando a percepção desses sujeitos que, de forma direta, têm construído esta realidade.

\section{Considerações finais}

A história da assistência psiquiátrica sempre esteve permeada por experiências de exclusão e estigmatização, sendo a possibilidade de resgate da cidadania um objetivo presente na construção das novas concepções do cuidado em saúde mental, daí a pertinência do uso da História Oral nas investigações dessa temática. A história oral dá voz a sujeitos anônimos, permite a revelação de acontecimentos, experiências e mentalidades que não se encontram nos documentos escritos (Janotti, 1996).

Suas características se conectam com pesquisas da área de saúde mental, uma vez que as transformações atuais no cuidado em saúde mental estimulam um novo papel social a estes que durante anos foram silenciados dentro de muros institucionais. A história oral possibilita que os diferentes protagonistas envolvidos nesse novo cuidado possam trazer para o conhecimento científico, histórias vividas e histórias em construção.

Pesquisar em saúde mental utilizando métodos e técnicas que potencializem as falas e histórias de seus atores enriquecem o saber científico e a produção desse saber e também dão sentido às práticas de saúde que tem em sua conceituação o compromisso ético com a vida e o ser humano em sua dimensão psicossocial.

\section{Referências}

Ayres, J. R. C. M. (2000). Cuidado: tecnologia ou sabedoria prática? Interface - Comunicação, Saúde, Educação, 4(6), 117-120.

Bosi, M. L. M.\& Mercado-Martínez, F. (2007). Introdução: notas para um debate. In: M. L. M. Bosi \& F. Mercado-Martínez (Orgs.). 
Pesquisa qualitativa de serviços de saúde. (pp. 23-71). 2ª ed. Petrópolis: Vozes.

Brêda, M. Z. , Ribeiro, M. C., Silva, P. P. A. C., Silva, R. C. O. \& Costa, T. F. (2011). A avaliação dos Centros de Atenção Psicossocial do estado de Alagoas: a opinião dos usuários. Revista da Rede de Enfermagem do Nordeste, 12(4), 818-824.

Campos R.O. \& Furtado J.P. (2008). Narrativas: apontando alguns caminhos para sua utilização na pesquisa qualitativa em saúde. In R. O. Campos, J. P. Furtado, E. Passos, R. Benevides. (Orgs.). Pesquisa avaliativa em saúde mental: desenho participativo e efeitos da narratividade. (321- 334). São Paulo: Aderaldo \& Rothschild.

Czeresnia, D. \& Freitas, C. M. (2003). Promoção de saúde: conceitos, reflexões, tendências. Rio de Janeiro: Editora Fiocruz.

Deslandes, S. F. (2008). Notas sobre a contribuição da sociologia compreensiva aos métodos qualitativos de avaliação. In R. O. Campos , J. P. Furtado \& E. Passos, R. Benevides. (Orgs.). Pesquisa avaliativa em saúde mental: desenho participativo e efeitos da narratividade. (68-77). São Paulo: Aderaldo \& Rothschild.

Ferreira, M. M. (1997). História oral, comemorações e ética. Projeto História. Ética e História oral, 15(1), 157-164. Recuperado em 15 agosto, 2011, de http: //cpdoc.fgv.br/producao_intelectual/arq/518.pdf.

Foucault, M. (2000). A arqueologiā do saber. 6. ed. Rio de Janeiro: Forense Universitária.

Grele, R. J. (2001). Pode-se confiar em alguém com mais de 30 anos? Uma crítica construtivista à história oral. In J. Amado, M. M. Ferreira. Usos \& abusos da história oral. (4ạ ed.) (pp.267277). Rio de Janeiro: FGV.

Haguette, T. M. F. (2010). Metodologias qualitativas na sociologia. 12. ed. Petrópolis: Vozes.

Janotti, M. L. M. (1996). Refletindo sobre a história oral: procedimentos e possibilidade. In: J. C. S. B. Meihy (Org). (Re)introduzindo história oral no Brasil. pp.56-62. São Paulo: Xamã.

J outard, P. (1983). Essas voces que llegan del pasado. México: Fondo de Cultura Económica.

Meihy, J. C. S. B. (2005). Manual de história oral. 5. ed. São Paulo: Edições Loyola.

Mendonça Filho, M. \& Vasconcelos, M. F. F. (2010). Questões de método e pesquisa dos dispositivos institucionais de confinamento do presente. Estudos e Pesquisas em Psicologia, $10(1), 134-150$.

Minayo, M. C. S. (2008). A utilização do método qualitativo para a avaliação de programas de saúde. Prefácio. In R. O. Campos, J. 
P. Furtado \& E. Passos, R. Benevides. (Orgs.). Pesquisa avaliativa em saúde mental: desenho participativo e efeitos da narratividade. (15-19). São Paulo: Aderaldo \& Rothschild.

Reinaldo, M. A. S., Saeki, T. \& Reinaldo, T. B. S. (2003). O uso da história oral na pesquisa em enfermagem psiquiátrica: revisão bibliográfica. Revista Eletrônica de Enfermagem, 5(2), 55-60. Recuperado em 18 agosto, 2011, de http://www.revistas.ufg.br/index.php/fen.

Schaiber, L. B. (1995). Pesquisa qualitativa em saúde: reflexões metodológicas do relato oral e produção de narrativas em estudo sobre a profissão médica. Revista Saúde Pública, 1(29), 63-74. Recuperado em 10 maio, 2011, de http://www.scielo.br/pdf/rsp/v29n1/10.pdf

Silva, V. P. \& Barros, D. D. (2010). Método história oral de vida: contribuições para a pesquisa qualitativa em terapia ocupacional. Revista de Terapia Ocupacional da Universidade de São Paulo, 21(1), 68-73.

Tavares, C. M. M. (2005). A interdisciplinaridade como requisito para a formação da enfermeira psiquiátrica na perspectiva da atuação psicossocial. Texto Contexto, 14(3), 403-410.

Thompson, P. (1992). A voz do passado: história oral. Rio de Janeiro: Paz e Terra.

\section{Endereço para correspondência \\ Mara Cristina Ribeiro}

Universidade Estadual de Ciências da Saúde de Alagoas

Campus Governador Lamenha Filho

Núcleo de Ciências Humanas, Sociais e de Políticas Públicas

Rua Dr. Jorge de Lima, 113, Trapiche da Barra, CEP 57010-000, Maceió- AL, Brasil

Endereço eletrônico: maracrisribeiro@gmail.com

\section{Ana Lúcia Machado}

Universidade de São Paulo

Escola de Enfermagem

Departamento de Enfermagem Materno-Infantil e Psiquiátrica

Av. Dr. Enéas de Carvalho, 419, CEP 05403-000, São Paulo - SP, Brasil

Endereço eletrônico: almachad@usp.br

Recebido em: 14/02/2012

Reformulado em: 15/06/2013

Aceito para publicação em: 26/06/2013

\section{Notas}

* Terapeuta Ocupacional. Doutora em Ciências. Professora Adjunta do Núcleo de Ciências Humanas, Sociais e de Políticas Públicas da Universidade Estadual de Ciências da Saúde de Alagoas. Maceió, AL, Brasil.

** Enfermeira. Livre Docente. Professora Associada do Departamento de Enfermagem Materno Infantil e Psiquiátrica da Escola de Enfermagem da Universidade de São Paulo. São Paulo, SP, Brasil. 